\title{
Addressing issues of need, adaptability, user acceptability and ethics in the participatory design of new technology enabling wellness, independence and dignity for seniors living in residential homes
}

\author{
Joan Cahill $^{1}$, Sean McLoughlin ${ }^{2}$, Michael O’ Connor ${ }^{2}$, Melissa Stolberg ${ }^{2}$, \& Sean \\ Wetherall $^{2}$ \\ ${ }^{1}$ Centre for Innovative Human Systems (CIHS), School of Psychology, Trinity \\ College Dublin, College Green, Dublin 2, Ireland. \\ cahilljo@tcd.ie \\ ${ }^{2}$ Oneview Healthcare, Blackrock Business Park, Co. Dublin, Ireland
}

\begin{abstract}
This paper reports on human factors research concerning the advancement of new technology facilitating seniors leading fulfilling, meaningful and independent lives, with dignity in the community. Specifically, this paper provides a roadmap for the specification of new technology for use in residential homes which seeks to establish the appropriate balance between enabling the independence and well-being of residents (including supporting their privacy) and protecting residents from potential hazards. This research adopts a stakeholder evaluation/participatory approach to requirements elicitation and user interface design. The technology is defined from the perspective of addressing specific end user and stakeholder needs, and achieving relevant states/benefits associated with wellbeing, successful ageing, and relationship centred care. This research is being undertaken as an industry/academia collaboration involving Trinity College Dublin (TCD) Ireland and Oneview Healthcare.
\end{abstract}

Keywords: Assisted living, Ageing and technology acceptance, Health care technologies and services for the elderly, Relationship centered care, Social connection, Stakeholder evaluation, Well-being, User acceptability, Ethics, Privacy.

\section{Introduction}

\subsection{Ageing \& Models of Successful Ageing}

Ageing is a normal part of life. Although certain diseases occur in old age, old age itself is not a disease. As we age, we face many changes and losses. This includes changes in physical health and cognitive ability, changes in way of life (and living environment), and loss of friends and family. Ageing and old age is also associated with maturity, wisdom and acceptance of life challenges. In addition, with in-

adfa, p. 1, 2011.

C Springer-Verlag Berlin Heidelberg 2011 
creased time availability, there is the potential for personal growth, strengthening social relationships and engaging in purposeful activity.

Biomedical models focus on the absence of chronic disease, independent physical functioning, performance, mobility, and cognitive functioning [1]. Rowe and Kahn distinguish between usual ageing/normal decline and successful ageing [2]. According to Rowe and Kahn, successful aging is multidimensional, encompassing the avoidance of disease and disability, the maintenance of high physical and cognitive function, and sustained engagement in social and productive activities [2]. Psychosocial models focus on life satisfaction, social participation, functioning, and psychological resources [3, 4]. Psychological resources include a positive outlook and self-worth, self-efficacy or sense of control over life, autonomy and independence, and effective coping and adaptive strategies in the face of changing circumstances [5]. Such psychological resources are important to maintaining positive mental health as we age. Seniors are at risk for developing anxiety and depression, given increased frailty, medical illnesses and medication and the potential for loss, reduced social connection and trauma (arising from injuries/accidents such as falls).

\subsection{Underpinning Concepts}

Discussions of ageing make reference to several theoretical concepts including well-being, autonomy, independence, quality of life, social connection and community. According to biopsychosocial models of health and well-being, medical and psychological factors, family and social factors are some of the different determinants impacting on a person's health and well-being [6,7]. This is supported by trends in the prescription of (1) physical activity, (2) social activity, (3) the practice of hobbies and artistic/cultural activity and (4) specific relaxation techniques (i.e. yoga and meditation), by physicians and other health practioners.

In relation to senior living, the concept of autonomy refers to exercising individual choice, freedom of will, and assuming responsible for one's own behavior and/or self [8]. As human relationships are based on mutual dependence and partnership [9], autonomy cannot be viewed as separate from the relationships within which individuals are embedded [10]. Accordingly, the concept of relational autonomy has been posited [11].

Independence is often discussed in the context of a senior's ability to complete specific activities of daily living (ADL). Basic ADLs consist of self-care tasks that include, but not limited to functional mobility, bathing and showering, dressing, self-feeding, personal hygiene and grooming and toilet hygiene. Instrumental activities of daily living (IADLs) are not necessary for fundamental functioning, but they let an individual live independently in a community. This includes housework, preparing meals, taking medications as prescribed, managing money, shopping for groceries or clothing, use of telephone or other form of communication and transportation within the community. Quality of life is a more nebulous concept, referring to the standard of health, comfort, and happiness experienced by an individual 
or group. Several studies substantiate the link between selfdetermination/autonomy and quality of life for seniors [12, 13].

A community is a most commonly referred to as a social unit or population living and/or interacting with one another in a specific environment. An individual's social relations/ties within a community are often characterized as either personal or professional. Theories of social capitol $[14,15,16]$, emphasize the enabling role of relevant actors within ones community, in terms of supporting both healthy behavior and behavior change.

\subsection{Care Models}

In care contexts, patients want a personal relationship, quality communication and empathy from medical/care professionals. To this end, patient-centered care replaces our current physician centered system with one that revolves around the patient [17]. Some argue that the concept of patient-centered care must be supplemented with the concept of person-focused care [18]. Patient-centered care focuses on visits involving care of generally chronic diseases [18]. In contrast, personfocused care 'extends beyond communication because much of it relies on knowledge of the patient (and of the patient population) that accrues over time and is not specific to disease-oriented episodes' [18]. More recently, there has been a move towards relationship centered care [19, 20, 21]. Advocates of relationship centered care emphasize the importance of personhood and relationships. As human beings are active relational beings, nurturing positive relationships is essential to well-being, and has a bearing on health care experiences and outcomes [22].

\subsection{Care Models \& Contexts/Settings}

According to research by the American Association of Retired Persons, nearly 90 percent of seniors want to stay in their own homes as they age [23]. 'Ageing in place' is associated with many positives, including the comfort of being in ones' own environment (with associated implications of user control and privacy), and enabling continuity/access in terms of social arrangements. However, the home is not always the ideal environment for fostering independence and quality of life. Studies also highlight the potential for social isolation [24] and disempowerment [25]. This is often the case, if the home is the location for medical treatment and service intervention [26]. Many seniors attend day service which usually involves commuting to a nearby health-care service facility (i.e. ambulatory care model). Such facilities offer a broad range of services outside the acute hospital system, including Primary Care, Social Care, Mental Health and Health \& Wellbeing Services. Continuing care retirement communities and/or assistive living refers to a system that provides a place to live and medical care for people (such as elderly or disabled people) who need help with daily activities. 


\subsection{Residential care \& Nursing Role}

Residential care/nursing homes provide twenty four hour care to seniors. The decision to transition into a residential care facility is frequently related to changes in health and/or personal circumstances (i.e. loss of spouse/partner or caregiver). Residential/care homes have been associated with certain negatives. For example, hospital-like rooms, regimented routines (i.e. lack of control in relation to when eat, wash, sleep and wake), lack of freedom, reduced social connection [27], boredom and issues adapting to privacy [28]. Others highlight a lack of purposeful activity (i.e. passive group entertainment), and a tendency to treat residents like preschool children, where life designed to be safe and supervised, but devoid of meaning [29]. A recent qualitative review of quality of life (QoL) in care homes identified four key themes affecting good QoL (1) acceptance and adaption to their living situation, (2) connectedness with others, (3) a homelike environment, and (4) caring practices [31]. As highlighted by Gawande [29], residential care facilities have historically addressed societal goals (for example, freeing up hospital beds, taking burdens off families, coping with poverty amongst elderly), as opposed to addressing the goals of those domicile in them.

While many nurses and care assistants report the value and dignity associated with their work, senior care is not without its own challenges. Physical and emotional fatigue, stress, burnout and compassion fatigue is a common experience for geriatric nurses and care assistants. In this regard, nursing goals of avoiding bedsores, maintaining weight and protecting a patient's safety, can be at odds with an individual's desire for personal freedom, strengthening social bonds and engaging in meaningful activity. To this end, charters of rights for seniors living in care homes have been advanced both generally [31] and in the memory care context [32].

More recently, there has been a 'culture change' in residential care. There is now more attention to relationships, resident preferences and promoting intergenerational contact/communications. The 'inside out' approach advocates the integration of the community with senior residents so as to support the socialization needs of all, while providing opportunities for more partnerships. As evidenced in the Eden project, the use of pets, plant- life and buddying systems (i.e. community volunteers) encourages meaningful activity and social relationships [33]. This in turn bolsters wellbeing and has an impact on health outcomes. Equally, evaluations of Green House programs (i.e. care facilities staffed by 24-hour caregivers with 8-10 bedrooms and common living rooms and dining rooms) indicate enhanced quality of life for residents [34].

\subsection{New Assisted Living Technologies}

New technologies are being advanced to support the needs of seniors living both independently and in assisted living contexts. In parallel, technologies are being advanced for other stakeholders - in particular, carer's, family/informal carers' and healthcare providers (i.e. GP, hospital, specialists and community nurses). Such technologies provide diverse functions including: self-management of health, care 
coordination, health information/care plan access, entertainment, communications, education, telecare, ADL monitoring, medication adherence, emergency alerting, exercise and diet management, fall prediction, wander management, security management, mood and well-being, life logging, wayfinding and digital signage, brain training, resident administration and room administration. Generally, this involves the use of a range of connected devices (i.e. TV, tablets, smart phones, wearables, environmental sensors).

In relation to the nursing role, new tools are being introduced to enhance the assessment of patient acuity (and associated management of nursing assignment/staffing), to support nurse rounding and allied care tasks, and to manage and report on work related stress [35].

In general, the new technologies outlined above follow from (1) certain broad spectrum technology trends (i.e. the Internet of things, sensors in everything, big data, interoperability of new technology), and (2) specific health care trends (i.e. connected health, electronic healthcare pathways, technology-enabled caregivers and ambient assisted living). In most cases, these technologies are underpinned by concepts of ageing in place, autonomy, personalized care, social capitol, community, social connection and quality of life. However, the specific technologies are not articulated in relation to specific health and well-being models (i.e. biopsychosocial), and models of successful ageing (i.e. biomedical, psychosocial or some combination of these).

\subsection{New Assisted Living Technologies: User Acceptability}

It is argued that the purpose and functionalities of gerontechnologies are often led by the requirements of their social and caregiving environments [36]. Often, their functionalities do not match their intrinsic motivations and expected benefits. This has an impact on user acceptance [36]. Acceptance is critical if technologies are to be embedded in a person's life [37]. Chen and Chan found that technology acceptance and usage behavior in elderly people are predicted by certain (1) user characteristics (i.e. age, education, gerontechnology related self-efficacy and anxiety, and health deficiencies), and (2) environmental factors (i.e. accessibility, assistance and guidance) [37], rather than attitudinal factors, as proposed in the technology acceptance model [38]. Research, by Lee, Lee and Hwang [39] illuminates the connection between self-determination and user acceptance. When technology supports self-determination, it positively impacts acceptance. That is, seniors are 'intrinsically motivated' by technology that promotes autonomy.

\subsection{New Assisted Living Technologies: Ethics}

Human beings value their privacy and the protection of their personal life [40]. The privacy debate has advanced with the development of information technology. Indeed, technological changes are influencing privacy norms [41]. Many of the available technologies pose fundamental questions in relation to ethics and user ac- 
ceptability. In advancing new AL technology, the following questions might be asked:

1. For whom is this technology for?

2. How should this technology be designed to deliver the appropriate benefits to seniors and other relevant stakeholders?

3. Whose rights need to be considered and who has priority?

4. How to the rights and need of seniors and other stakeholders interrelate?

\section{Methods \& Research Status}

\subsection{Research Design}

This is an action research study combining several qualitative research methods including ethnography (interviews and observations) and participatory design [42]. Overall, the human factors design approach is premised on the assumption that solutions for seniors and other actors are necessarily interrelated. As such, a stakeholder evaluation based approach is adopted [43]. Human factors research involves active and ongoing participation of end users (i.e. seniors) and other key stakeholders. As detailed in Table 1, system development follows several iterative activities pertaining to (1) needs analysis, benefits analysis, processing mapping and requirements elicitation, (2) user interface design prototyping and (3) evaluation.

Table 1: Research Phases \& Activities

\begin{tabular}{|l|l|l|}
\hline$\#$ & Research Phases/Activities & Stakeholder Involvement \\
\hline 1 & $\begin{array}{l}\text { Literature analysis (theory, research pro- } \\
\text { jects, competitors/industry) }\end{array}$ & Internal stakeholders \\
\hline 2 & $\begin{array}{l}\text { Preliminary definition of philoso- } \\
\text { phy/approach, concept, high level re- } \\
\text { quirements and associated personae spec- } \\
\text { ification }\end{array}$ & Internal stakeholders \\
\hline 3 & $\begin{array}{l}\text { Requirements elicitation (interviews and } \\
\text { observations with end users and stake- } \\
\text { holders) and process mapping }\end{array}$ & External Stakeholders \\
\hline 4 & $\begin{array}{l}\text { Elaboration of concept and philosophy } \\
\text { and specification of detailed require- } \\
\text { ments and personae }\end{array}$ & Internal stakeholders \\
\hline 5 & User interface design prototyping & Internal stakeholders \\
\hline 6 & Co-design and evaluation & Internal \& External Stakeholders \\
\hline 7 & Final specification and design & Internal \& External Stakeholders \\
\hline
\end{tabular}

Certain research phases are sequential (phases 1 and 2), while others are running in parallel (to an extent) and iterative (phases 3, 4, 5 and 6).

In relation to needs and benefits analysis, interviews and observations are being undertaken with end users and other stakeholders. The methodological approach is underpinned by phenomenological approaches to eliciting information about 'lived experience' [44], and specifically, interpretative Phenomenological Analysis [45]. 
The emphasis is on understanding the context and meaning of experience, and in particular, the interactions between seniors and relevant stakeholders in their personal and professional community (i.e. family members, carer's, friends, GP etc). In relation to participatory design activities, the methodology draws upon person centered design approaches - specifically, 'personae based design' [46], and 'Scenario Based Design' [47]. Personae's have been advanced for seniors in different contexts. This ensures that the proposed technology will take into account (1) the experiences and needs of end users in different settings and situations (i.e. lifespan perspective - home, assisted living community), and (2) the specific needs of end users and other stakeholders in the residential care context.

Further, as depicted in figure 1, bowties are used to elicit and validate technology requirements in relation to addressing latent conditions and states/benefits to be achieved. Specifically, the bowties enable joint/collective problem solving with respect to user need/requirements and user interface design solutions. Co-design activities focus on how the proposed technology installs barriers to (1) prevent the event from occurring and, (2) to recover the situation, if the hazard is encountered (thereby reducing/mitigating the consequences of the hazardous event).

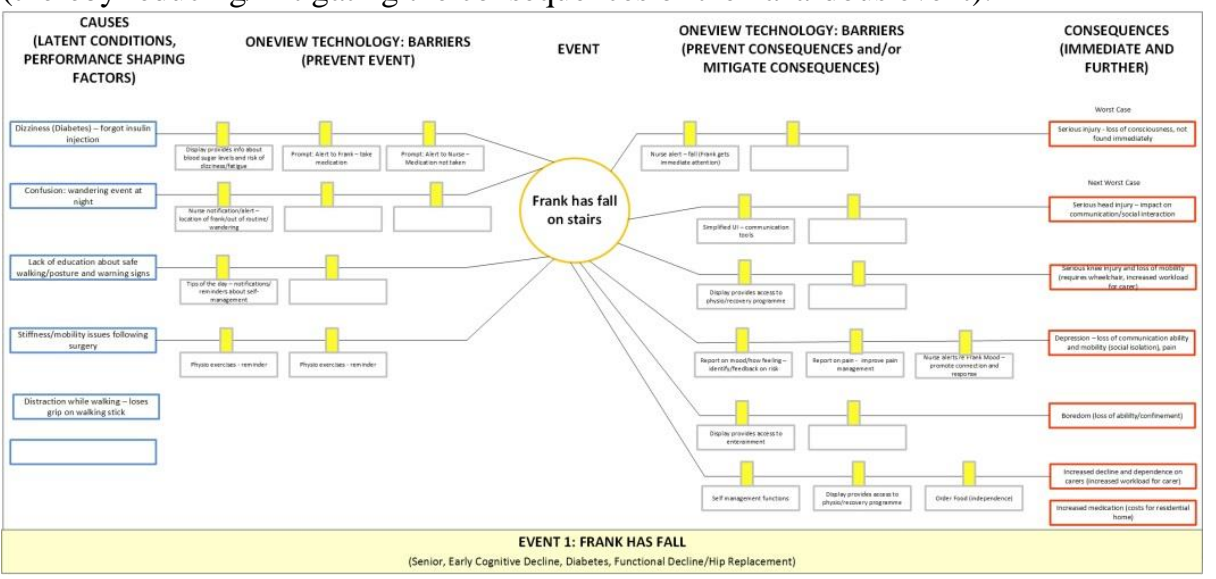

Figure 2: Bow Tie (Frank has fall).

There are two strands of evaluation, (a) ongoing participatory design/evaluation with stakeholders, and (b) discrete evaluation using an aged care Living Lab. The qualitative data analysis software NVivo is being used to support the thematic analysis of data relating to lived experience and need. Following, the analysis of all data, co-design activities will be undertaken with the participant panel (internal and external stakeholders).

\subsection{Community of Practice \& Participant Profiles}

In support of stakeholder design/evaluation activities, a 'Community of Practice' (COP) [48] has been formed comprising both internal and external stakeholders. As detailed in Table 1 above, both internal and external stakeholders participate in different research activities. Internal stakeholders $(\mathrm{N}=10)$ include members of the 
assisted living project/research team (i.e. human factors researchers, user experience designers, developers, product owners, clinicians, nurses and experts in health informatics). External stakeholder comprises two participant groups (1) end users and (2) other stakeholders ( $N=30$ to 40 participants). (1) End users are split into four sub-groups - comprising seniors living independently and living in residential homes, potentially living with one or more morbidities, with different levels of functional and cognitive ability and an age range of 60 to 90 years. (2) Other stakeholders include three sub-groups, (a) family members, (b) formal aged care staff - (i.e. aged care nurses, care assistants and community nurses) and (c) other stakeholders (i.e. GPs, geriatricians, experts in ageing, volunteers in active ageing groups and volunteers/staff of relevant groups/societies). In terms of the research design, the participants are being considered as independent of each other. End users and other stakeholders are participating in research phases 3, $6 \& 7$.

\subsection{Research Status}

Research phases 1 and 2 are complete and phases 3, 4 and 5 are currently underway (these are running in parallel and iterative). Interviews and observations have provided feedback about lived experience, stakeholder need, expected benefits and underlying process facilitators and blockers. Personae's have been defined for different end users and stakeholders, in specific contexts including residential care, home-care, assisted living and palliative care. High level requirements have also been defined (see Appendix 3). Preliminary prototypes for (1) seniors and (2) nurses have been defined. These will be further elaborated in co-design activities (see Appendix $5 \& 6$ ). It is anticipated that co design activities with end users and other stakeholders (phase 6 research) will enable problem solving around need and issues pertaining to acceptability/ethics.

\section{$3 \quad$ Results}

\subsection{Lived Experience of Seniors}

The lived experience of seniors (and associated perceived quality of life and autonomy) varies according to a senior's overall life course, individual characteristics, activity levels (i.e. level of self-care and requirement for assistance) and levels of social interaction. In relation to levels of physical and social activity, this usually depends on the older person's general health (i.e. if managing one or more morbidities), physical/functional ability and cognitive ability (i.e. level of cognitive decline). The availability of family and friends in relation to transportation support has an impact on attendance at 'outside' social events.

Adaptation is a feature of the ageing experience (i.e. concentrating on strengths rather than weaknesses). Seniors use many strategies to cope with loss of function/independence and change. This includes the use of external aids (i.e. walking frames), getting help from others, engagement in purposeful activities (i.e. bridge, 
gardening, volunteering, bowling and dancing) and social participation (i.e. attendance at community and family events). Overall, there is an interest in active and healthy ageing.

In different contexts (home and residential care), loneliness and boredom is a common experience. Spending time and interacting/communicating with family members and friends is highly valued. Such social engagement supports a sense of 'belonging', 'having a role' and 'feeling needed'.

The transition to residential care is often precipitated by health changes (i.e. worsening illness) and different care constraints (i.e. key family member's not living close-by, difficulties of providing suitable 24 hour care in the home and so forth). This decision is usually made with family members. There is often significant apprehension in relation to transitioning to residential care. This includes fear in relation to loss of control over daily activities, loss of privacy and loss of identity.

\subsection{Community Concept}

Well-being is strongly influenced by the quality of a senior's relationships with members of their personal and professional community. Specifically, different members of a person's community can be associated with different spheres of well-being albeit these are all related. A senior's personal community includes family members, friends, neighbors and members of active retirement groups. The professional community includes care assistants, nurses, Dr's, specialists, hairdressers and the postman.

\subsection{Stakeholder Need, Benefits \& States}

\section{Seniors}

Seniors represent a diverse group with different physical and cognitive abilities and needs. Successful ageing is multidimensional and includes psycho social elements. In this regard, research outlines several states (1) to be promoted, (2) to be managed and/or mitigated and (3), to be avoided. For more, please see Appendix 2. Seniors want more than just safety and care support (i.e. ADL's, management of disease). In general, seniors want to avoid 'being a burden' for friends and family. Seniors want care with dignity and choice. They want the option to live as independently as possible - while availing of community/ambulatory services when required. Overall, there is a strong need for self-fulfillment, being mentally aware and strengthening relationships with friends and family. In both home and residential settings, seniors miss friendship, having a purpose to their day and being needed. There is an interest in fostering independent and purposeful activities (i.e. not just formal events in the residential home), and to promote organically occurring activities between residents. The risk of personal injury (and specifically injuries from falls) is a big concern for seniors both in home and residential contexts. In general, seniors are keen to improve their own health literacy and to adopt selfmanagement approaches. This provides a degree of self-fulfillment and autonomy.

\section{Carer's \& Family}


For carer's and family members, systems should support relevant care and activity/safety monitoring tasks, along with enabling empathy and social connection. Technology might support resident transition to the new care situation. For example, it might be used to familiarize the resident with the new environment, care routines, how technology is used, and how privacy is addressed (thereby managing fear and supporting their ability to deal with change). Further, preferences, interests and their personal story might be elicited at the beginning, and recorded in an electronic resident record. Providing care staff with information about 'who they are' and 'what matters to them' might enhance care activity and ensure that structured leisure activities are both meaningful and purposeful. From a nursing perspective, future systems might address issues around assessing patient acuity and enabling efficient and real-time access to resident information. Electronic rounding systems might capture well-being information (i.e. level of physical activity, pain, sleep, diet and social activity). It is anticipated that this will support quality care delivery, particularly in high workload periods. Further, it will address fatigue and stress management (thereby mitigating/reducing burn-out). In addition, such systems might enable nurse interaction with family members and other clinicians and specialists (both on and off site).

\section{GP \& Specialists}

Integration of health documentation is a key need for both primary and secondary care providers.

\subsection{Ethics, Privacy \& User Acceptance}

Future systems should not be used to replace person centred care and/or to reduce the time that nursing and care staff spend with residents. Such systems should respect a senior's privacy and choice. Residents should have control over the personal sphere - including any information captured about the biopsychosocial dimensions of their health and well-being. Residents should have the option to opt in and out of sensors. Appendix 4 includes a list of issues/considerations in relation to ethics and user acceptability.

\subsection{Initial Concept, Preliminary Requirements \& User Interface Design}

Overall, the concept is to develop a range of self-decided services (opt in/out), based on what matters to older people, and to allow for personalization. The proposed functionality is (1) conceptualized in relation to stakeholder relationships. According, there a suite of inter-related technologies are being advanced for seniors and other stakeholders (i.e. nurses, family members, GP etc). The proposed technology (2) addresses all three pillars of well-being and the interrelationship therein. Specific functions promote wellness and map to the underpinning biopsychosocial model of health and well-being. Further, (3) the functionality takes into account models of successful ageing - supporting social participation, addressing stress, mood and engagement, providing entertainment functions and promoting 
self-management and purposeful ageing. For more, see Appendix 3. Moreover, (4) the availability and level of personalization reflects an 'ability' philosophy.

The design solution is adaptive in terms of age-related changes and characteristics (see Appendix $5 \& 6$ ). The design concept avoids known problems with current WIMP (windows, icons, menus, point-and-click devices). Interactions are natural using touch (and potentially speech and gesture). At present, outputs are primarily text/image based. Research is currently addressing multimodal aspects - voice synthesis and haptics. It is intended that design interactions will be natural and engaging. It is not likely that mid to late stage memory care patients, will have significant interaction with Tablet/TV systems. Here the focus will be on delivering smart and emphatic solutions for carer's and family. Critically, solutions for these actors will yield benefits for memory care patients.

\section{Discussion}

\subsection{Role of Technology}

In a residential context, technology has a role beyond that of (1) managing and reporting on a resident's physical health and security (and associated clinical and care tasks), and (2) supporting operational and organisational goals (for example, staffing, risk management and compliance). Technology has a role in terms of supporting the well-being of both patients and staff alike, enabling life/job satisfaction and social participation, and fostering an environment that provides a sense of purpose for all (i.e. residents, staff and families).

Importantly, future technology has the potential to address (and possibly ameliorate) many of the issues identified in relation to quality of life, user control and privacy in care homes. As mentioned previously, technology can be used to familiarize the resident with the new environment, care routines, technology usage and procedures in relation to privacy - thereby supporting a senior's ability to deal with change. Technology can improve care practices and quality of care by enabling holistic approach to care delivery and reporting (i.e. biopsychosocial). Intelligent and unobtrusive sensors can be embedded in the environment. Lighting and door locking can reflect user need and patterns (linked to data analytics). In principle, the provision of choice in relation to meal selection, supporting self-decided activities, enabling organically developed social relationships goes a significant way towards fostering independence. However, we cannot simply pay lip service to the idea of autonomy. This needs to extend into data protection practices and staff/care procedures too.

\subsection{Technology Enabling Relationship Centered Care}

Relationship centered care provides the framework for thinking about need, and the context for thinking about concepts such as independence, quality of life and community. As stated earlier, independence (and quality of life for seniors) is 
linked to interdependence (i.e. support from other actors in a senior's personal and professional community). The different care models outlined previously focus on personhood and nurturing social/care relationships. By implication, future technology needs to consider both (1) the person and (2) enabling positive relationships and communications between seniors and relevant actors in their personal and professional community. Specifically, the achievement of benefits in relation to resident experience, autonomy and well-being, is dependent on situating technology development in the context of enabling these relations. There are issues/barriers on both sides and these must be addressed in a 'joined up' way. This is not necessarily straightforward. Critically, it requires a commitment to a 'relationship centred' approach, underpinned by ethical principles centred on respect for seniors and their circle of care. Overall, the approach is to develop technology from the perspective of understanding the relationship/interdependencies between different stakeholders. These interdependencies are modelled in terms of workflow and user interface design, so that the states/lived experience outlined in Appendix 2 are realized. Further, this stakeholder approach has implications in terms of the overall technology offering. Future assisted living technology cannot be advanced for seniors alone. Corresponding applications are required for other relevant stakeholders with whom seniors communicate/have interactions with. It is this communication/interaction that has an impact on well-being and health. This is the key to promoting the positive states as outlined in Appendix 2.

\subsection{Focus on personhood}

Technology has the potential to (1) support personhood, and (2) enable both person-centered and relationship centered care by (a) eliciting the right information at the right time about relevant actors (i.e. resident's, carer's and their families), and (b) sharing this information at the right time with relevant actors. Critically, this frees up time for value based care practices and meaningful social interactions. The advancement of person centred resident records which address the three pillars of well-being (i.e. biological, psychological and social) and includes detailed information about life history and what matters to the resident is critical. This should be supplemented by real-time information about the resident, so a dynamic and evidence based profile is captured. This 'live' record can form the basis for all social and clinical interactions with the resident (and their families) and associated decisions. For example, if the resident completes a wellness report, this information should be made available to the nurse so that he/she is armed with the right information, to enable meaningful care/social interactions. Further, self-report data can be coupled with observational data and data arising from any clinical assessments. Over time, a rich picture of the resident and their wellness can be advanced - facilitating person centered and relationship centered care. Equally, the provision of real-time access to health, well-being and medication information captured by different actors (i.e. GP's, specialists, pharmacists, occupational therapists, dieticians, psychologists, psychiatrists, well-being coaches etc) enables person centred care. 
Evidently, if seniors are to use this technology, then the benefits need to map to what matters to them (i.e. appeal to intrinsic motivation). It is anticipated that the direct experience of benefits in relation to quality of life, social connection and improved care practices will be a motivating influence for seniors. As is evidenced in the Eden project and others, such benefits have knock on impact in relation to resident medication requirements, mortality rates, along with staff workload and retention.

\subsection{Ethics \& User Acceptability}

Technology should not be used to minimize or replace person centered care. Further, it should reflect a careful balance between optimizing the ability/strengths of the person, while taking into account the needs (and workload) of carer's. This technology will be implemented in different care contexts with different business models (i.e. for profit/not for profit, government funding). The motivation for introducing such technologies may vary and there is the potential that organizational needs (i.e. staff costs, keeping residents safe) may conflict with end user needs (i.e. independence, privacy and social interaction). It is important that residents have the option to opt in/out of the use of sensors. The role and use of data analytics in terms of (1) tracking and responding to an individual resident's clinical needs and (2) addressing issues relating to managing risk/safety, needs to be carefully considered. Where possible, resident consents should be established in relation to who has permission to access resident data and how this data is used. In certain cases, different interests may need to be balanced (i.e. memory care).

\subsection{Technology is one part of the solution}

The objective is to advance technology which supports well-being, successful ageing, and relationship centred care (and associated positive behaviors for relevant end users and stakeholders). It is important to be mindful of the complexities and challenges of ageing, and the opportunities to advance technology which manages and mitigates potential challenging states and behaviors. Technology is only one part of the solution, and does not replace person centered interaction/care. Further, the implementation of new assisted living technology needs to take into account other socio-technical dimensions (i.e. people, process, environment, culture and training). Relationship/patient centered care necessitates happy well trained staff, working with the right level of resources (i.e. staffing, equipment) and supported by person friendly processes that foster communication, trust and open disclosure.

\section{Conclusions}

There are need/benefits on different sides (i.e. residents, families, Dr's, nurses and care assistants). Evidently, supporting resident autonomy, independence and quality of life is important. However, such autonomy cannot be conceptualized outside 
an understanding of the relationships seniors have in their personal and professional community. Independence (and quality of life for seniors) is linked to interdependence (i.e. support from other actors in a senior's personal and professional community). Accordingly, the approach is to develop technology from the perspective of understanding, modelling and transforming the social, information and process relationships between seniors and associated stakeholders in the community.

The overall technology solution is predicated on (1) successful models of ageing, and (2) biopsychosocial models of well-being. Further, it directly addresses (3) the lived experience/states to be achieved for relevant end users and stakeholders. Further, (4) it is based on an ability philosophy. Overall, the outlook is positive - there is a strong potential for using assisted living technology to deliver on these states, both directly and indirectly.

Future assisted living technology should promote active ageing, engagement with life, independent living, self-management of health, well-being and mental health awareness. Such technology should be predicated on positive accounts of ageing and avoid ageism and negative stereotypes. The future is positive. New technology affords the possibility for improved social relationships, better quality of care and user control/independence, in residential care contexts. Nonetheless, such technologies require careful consideration in relation to ease of use, adapting to age/condition and issues around ethics and user acceptability. Seniors should be able to opt in and opt out of all services. Critically, the proposed technology must uphold people's dignity and supports their right to make their own choices (promoting independence and quality of life).

\section{References}

1 Seeman TE, Charpentier PA, Berkman LF, Tinetti ME, Guralnik JM, Albert M, et al. (1994). Predicting changes in physical performance in a highfunctioning elderly cohort. MacArthur studies of successful aging. J Gerontol 1994;49:M97-108.

2 Rowe JW, Kahn RL.(1998). Successful aging. New York: Pantheon Books.

3 Silverstein M, Parker MG. (2002). Leisure activities and quality of life among the oldest old in Sweden. Res Aging 2002; 24: 528-47.

4 Leonard WM. (1981). Successful aging: an elaboration of social and psychological factors. Int J Aging Hum Dev 1981-2; 14: 223-32.

5 Bowling A \& Iliffe S. (2006). Which model of successful ageing should be used? Baseline findings from a British longitudinal survey of ageing. Age Ageing 35: 607-14.

6 Engel, G. (1977). The need for a new medical model: a challenge for biomedical science. Science, 196:126-9.

7 Havelka M, Lucanin J, D. \& Lucanin D (2009). Biopsychosocial model - the integrated approach to health and disease. Coll Antropol. Mar;33(1):303-10 
8 Rodgers, V., and Neville, S. (2007). 'Personal autonomy for older people living in residential care: an overview'. Nursing Praxis in New Zealand 23.1 (2007): 29.

9 Barnes M, Blom A, Cox K. (2006). The social exclusion of older people: evidence from the first wave of the English Longitudinal Study of Ageing (ELSA): final Report. Office for the Deputy of Prime Minister.

10 Perkins, M. M., Ball, M. M., Whittington, F. J., \& Hollingsworth, C. (2012). Relational Autonomy in Assisted Living: A Focus on Diverse Care Settings for Older Adults. Journal of Aging Studies, 26(2), 214-225.

11 Hillcoat-Nallétamby, S., (2014). The meaning of "independence" for older people in different residential settings. Journals of Gerontology, Series B: Psychological Sciences and Social Sciences, 69(3), 419-430.

12 Ferrand, G. Martinent, N. Durmaz. (2014). Psychological need satisfaction and well-being in adults aged 80 years and older living in residential homes: Using a self-determination theory perspective. Journal of Aging Studies, 30 (1) (2014), pp. 104-111.

13 O Connor, B., P. \& Vallerand, R., J. (1994). Motivation, self-determination, and person environment fit as predictors of psychological adjustment among nursing home residents. Psychology and Aging, Vol 9(2), Jun 1994, 189-194.

14 Bourdieu, P. (1986), 'The Forms of Capital', in Richardson, John G., ed., Handbook of Theory and Research for the Sociology of Education, New York: Greenwood. Putnam RD.

15 Putnam, R. D. (2000). Bowling alone: The collapse and revival of American community. New York: Simon \& Schuster.

16 Morgan A \& Swann C (eds) (2004.) Social capital for health: Issues of definition, measurement and links to health. London: Health Development Agency.

17 Institute of Medicine. (2001). Crossing the Quality Chasm. Crossing the Quality Chasm: A New Health System for the 21st Century. Washington, D.C: National Academy Press.

18 Starfield, B. (2011). Is Patient-Centered Care the Same As Person-Focused Care? The Permanente Journal, 15(2), 63-69.

19 Kitwood, T. (1997) Dementia reconsidered: the person comes first, Buckingham: Open University Press.

20 Nolan M. (2002) Relationship-centred care: towards a new model of rehabilitation. Int J Ther Rehabil. 2002; 9:472-7.

21 Soklaridis, S., Ravitz, P., Adler, G., Nevo, A., Lieff, S. (2016). Relationshipcentered care in health: A 20-year scoping review, Patient Experience Journal Volume 3, Issue 1 - Spring 2016, pp. 130-145.

22 Beach M., C \& Inui T. (2006). Relationship-Cantered Care Research Network. Relationship-centered care: A constructive reframing. J Gen Intern Med. 2006; 21 Suppl 1:S3-8.

23 American Association of Retired Persons. (2011). Aging in Place: A State Survey of Livability Policies and Practices A Research Report by the Na- 
tional Conference of State Legislatures and the AARP Public Policy Institute, AARP Public Policy Institute, Washington.

24 Milligan, C. (2009). There's no place like home : place and care in an ageing society. (1st ed.) Farnham: Ashgate.

25 Rabiee P. (2012). Exploring the relationships between choice and independence: Experiences of disabled and older people. British Journal of Social Work , 1-17.

26 Baldwin N. Harris J. Kelly D. (1993). Institutionalisation: Why Blame the Institution? Ageing \& Society , 13, 69-81.

27 Kane RA. (2003). Definition, Measurement, and Correlates of Quality of Life in Nursing Homes: Toward a Reasonable Practice, Research, and Policy Agenda. The Gerontologist 2003; 43 Special Issue II: 28-36.

28 Forbes-Thompson S, Gessert CE (2006). Nursing Homes and Suffering: Part of the Problem or Part of the Solution? Journal of Applied Gerontology 2006; 25: 234-252.

29 Gawande, A (2015). Being Mortal: Illness, medicine and what matters in the end. Profile Books, London.

30 Bradshaw S. A, Playford E. D, Riaz A. (2012). Living well in care homes: a systematic review of qualitative studies. Age and Ageing. 2012;4:429-440.

31 European Commission (2010), European Charter of Rights and Responsibilities of older people in need of long term care and assistance.

32 Alzheimer's Society (2013). Human Rights and Older People in Ireland (Policy Paper), December 2013.

33 Ransom, S. (2000). Eden alternative: The Texas Project. Retrieved January 20, 2016, from https://digital.library.txstate.edu/handle/10877/4087.

34 Kane, R. A., Lum, T. Y., Cutler, L. J., Degenholtz, H. B., \& Yu, T. C. (2007). Resident outcomes in small-house nursing homes: A longitudinal evaluation of the initial green house program. Journal of the American Geriatrics Society, 55, 832-839.

35 Frost and Sullivan. (2015) Acuity-Based Staffing as the Key to Hospital Competitiveness: Why the Smartest Hospitals are Tying their Nurse Labor Investment to Patient Care. Frost \& Suillivan White Paper. Retrieved January 20, 2016, from http://www.quadramed.com.

36 Dupuy, L., Consel, C. \& Sauzéon H. (2016), Self determination based design to achieve acceptance of assisted living technologies for older adults. Computers in Human Behavior 65, 508-521.

37 Chen, K. \& Chan. A.H.S. (2011). A review of technology acceptance by older adults. Gerontechnology, 10 (2011), pp. 1-12.

38 Davis, F. D. (1989). Perceived usefulness, perceived ease of use, and user acceptance of information technology. MIS Quarterly, 13(3), 319-339.

39 Lee Y., Lee J., Hwang Y. (2015). Relating motivation to information and communication technology acceptance: Self-determination theory perspective. Computers in Human Behavior, 51, 418-428.

40 van den Hoven, Jeroen, Blaauw, Martijn, Pieters, Wolter and Warnier, Martijn (2016). "Privacy and Information Technology", The Stanford Encyclo- 
pedia of Philosophy (Spring 2016 Edition), Edward N. Zalta (ed.). Retrieved 20 January 2017 from <http://plato.stanford.edu/archives/spr2016/entries/itprivacy.

41 Boenink, M., T. Swierstra, \& D. Stemerding. (2010). "Anticipating the interaction between technology and morality: a scenario study of experimenting with humans in bionanotechnology", Studies in Ethics, Law, and Technology, 4(2): 1-38.

42 Bødker, S., \& Burr, J. (2002). The Design Collaboratorium. A Place for Usability Design. ACM Transactions on Computer Human Interaction, 9(2), 152-169.

43 Cousins, J. B., Whitmore, E., \& Shulha, L. (2013). Arguments for a Common Set of Principles for Collaborative Inquiry in Evaluation. American Journal of Evaluation, 34(1), 7-22.

44 Lindseth, A., \& Norberg, A. (2004). A phenomenological hermeneutical method for researching lived experience. Scandinavian journal of caring sciences, 18(2), 145-153.

45 Smith, JA and Osborn, M (2008) Interpretative phenomenological analysis. In JA Smith (Ed) Qualitative Psychology: A Practical Guide to Methods (second ed) London: Sage.

46 Pruitt, J \& Jonathan Grudin (2003), "Personas: Practice and Theory", Proceedings of the 2003 Conference on Designing for User Experiences.

47 Carroll, J.M. (1995). Scenario-based design: Envisioning work and technology in system development. John Wiley and Sons, New York.

48 Wenger, E. (1998). Communities of practice: Learning, meaning, and identity. Cambridge: Cambridge university press.

\section{$7 \quad$ Appendices}

\subsection{AL Stakeholders \& Community Concept}

Table 1: list of Stakeholders

\begin{tabular}{|l|l|l|}
\hline Stakeholder & Category & Persona \\
\hline \multirow{4}{*}{$\begin{array}{c}\text { Senior } \\
\text { primary end user) }\end{array}$} & Active and healthy senior & Richard \\
\cline { 2 - 3 } & Senior with early stage functional decline & Anne \\
\cline { 2 - 3 } & Frail elderly/senior & Lucy \\
\cline { 2 - 3 } & $\begin{array}{c}\text { Senior with early cognitive decline and under- } \\
\text { lying morbidity/medical condition }\end{array}$ & Frank \\
\cline { 2 - 3 } & Memory care patient (early stage dementia) & Tom \\
\cline { 2 - 3 } & Memory care patient (middle stage dementia) & Zena \\
\cline { 2 - 3 } & Memory care patient (late stage dementia) & Edward \\
\hline \multirow{3}{*}{$\begin{array}{c}\text { Personal Com- } \\
\text { munity }\end{array}$} & Spouse 1 (male) & Barry \\
\cline { 2 - 3 } & Spouse 2 (female) & Emily \\
\cline { 2 - 3 } & Family/daughter & Jane \\
\cline { 2 - 3 } & Buddy from local school community pro- & Peter \\
\hline
\end{tabular}




\begin{tabular}{|c|l|l|}
\hline \multirow{4}{*}{} & gramme & \\
\cline { 2 - 3 } & Friend & Alan \\
\cline { 2 - 3 } & Neighbour & Paul \\
\cline { 2 - 3 } $\begin{array}{c}\text { Professional } \\
\text { Community }\end{array}$ & Other residents (care home/residential home) & Jenny \\
\cline { 2 - 3 } & Gardener/maintenance & Bob \\
\cline { 2 - 3 } & Club member & Susan \\
\cline { 2 - 3 } & Formal carer (care assistant/nurse) & Angela \\
\cline { 2 - 3 } & GP & Kate \\
\cline { 2 - 3 } & Pharmacist & Robert \\
\cline { 2 - 3 } & Community Nurse & Sandra \\
\cline { 2 - 3 } & Care service/community (administration) & Louise \\
\cline { 2 - 3 } & Emergency Room Doctor & Mike \\
\hline
\end{tabular}

\subsection{Appendix 2: Lived Experience, States \& Benefits}

Table X: Lived Experience, States \& Benefits

\begin{tabular}{|c|c|c|}
\hline Promote/Support & $\begin{array}{l}\text { Manage/Mitigate \& } \\
\text { Reduce }\end{array}$ & Avoid \\
\hline $\begin{array}{l}\text { Quality of life } \\
\text { Wellness } \\
\text { Independence } \\
\text { Social participation } \\
\text { Privacy and protection of } \\
\text { personal sphere } \\
\text { Communication } \\
\text { Safety } \\
\text { Ability } \\
\text { Identity } \\
\text { Empowering person } \\
\text { Dignity/respect } \\
\text { Purposeful activity } \\
\text { Active and healthy living } \\
\text { Sense of continuity } \\
\text { Sense of belonging } \\
\text { Sense of purpose } \\
\text { Sense of usefulness } \\
\text { Acceptance } \\
\text { Resilience/coping } \\
\text { Self-management of health } \\
\text { Engagement } \\
\text { Calmness } \\
\text { Sense of confidence } \\
\text { Awareness (including senso- } \\
\text { ry awareness) }\end{array}$ & $\begin{array}{l}\text { Loss of identity } \\
\text { Loss of privacy } \\
\text { Loss of physical liberty } \\
\text { Physical discomfort } \\
\text { Communication difficul- } \\
\text { ties } \\
\text { Fear } \\
\text { Boredom } \\
\text { Sense of powerlessness } \\
\text { Difficulty with new in- } \\
\text { formation } \\
\text { Difficulty with change } \\
\text { Restlessness } \\
\text { Feeling lost } \\
\text { Overstimulated } \\
\text { Stress } \\
\text { Apathy/loss of interest } \\
\text { Wandering } \\
\text { Frustration } \\
\text { Confusion } \\
\text { Agitation } \\
\text { Negative thinking } \\
\text { Depression } \\
\text { Aggression/anger } \\
\text { Sleep disturbances and } \\
\text { sun downing }\end{array}$ & $\begin{array}{l}\text { Deception } \\
\text { Infantilization } \\
\text { Isolation } \\
\text { Elder abuse } \\
\text { Objectification of the } \\
\text { dementia patient } \\
\text { Unsafe behaviour } \\
\text { Reduction in human } \\
\text { contact } \\
\text { Neglect } \\
\text { Other... }\end{array}$ \\
\hline
\end{tabular}




\begin{tabular}{|l|l|l|}
$\begin{array}{l}\text { Nurturing person } \\
\text { Citizen participation }\end{array}$ & $\begin{array}{l}\text { Suspicion and delusions } \\
\text { Self-neglect }\end{array}$ & \\
\hline
\end{tabular}

\subsection{Appendix 3: Proposed High Level Technology Functions/Requirements}

Table X: Technology Functions

\begin{tabular}{|l|l|}
\hline$\#$ & High Level Function/Requirement \\
\hline 1 & Activity monitoring \\
\hline 2 & Wellness reporting (include mood, pain, sleep/fatigue, social activity, eating etc) \\
\hline 3 & Social engagement and events \\
\hline 4 & Communications \\
\hline 5 & Entertainment \\
\hline 6 & Emergency Alerting \\
\hline 7 & Education and coaching \\
\hline 8 & Care plans, care records, care co-ordination \\
\hline 9 & Telecare \\
\hline 10 & Medication management \\
\hline 11 & Reporting (care needs, problems, safety events) \\
\hline 12 & Exercise and wellness \\
\hline 13 & Nutrition and Meal ordering \\
\hline 14 & Wander management \\
\hline 15 & Wayfinding and digital signage \\
\hline 16 & Storytelling/life logging \\
\hline 17 & Transport co-ordination \\
\hline
\end{tabular}

\subsection{Appendix 4: Issues Pertaining to User Acceptability \& Ethics}

\begin{tabular}{|c|c|c|}
\hline \# & Issue & Examples \\
\hline 1 & $\begin{array}{l}\text { Privacy and } \\
\text { use of technol- } \\
\text { ogy }\end{array}$ & $\begin{array}{l}\text { Use of close circuit television (CCTV) to record resident activi- } \\
\text { ty/behavior in own rooms, social rooms, in corridors, in gardens } \\
\text { Use of wearable sensors to track resident movement and falls } \\
\text { Use of bed sensors to track activity at night } \\
\text { Use of RFID tags - tracking identity and location } \\
\text { Use of wearables - biomarkers (track health condition and risk) }\end{array}$ \\
\hline 2 & $\begin{array}{l}\text { Protecting dig- } \\
\text { nity and au- } \\
\text { tonomy }\end{array}$ & $\begin{array}{l}\text { Should a senior be able to opt out of the use of ambient sensors? } \\
\text { Of the personal information recorded about a senior, what in- } \\
\text { formation should be treated as sensitive? } \\
\text { If a family is paying for a loved persons care, should the family } \\
\text { interest in accessing their loved ones clinical/care data, super- } \\
\text { sede the senior's right to privacy? }\end{array}$ \\
\hline 3 & $\begin{array}{l}\text { Encroachment } \\
\text { on moral au- } \\
\text { tonomy }\end{array}$ & $\begin{array}{l}\text { If lack of privacy can expose seniors to outside forces that influ- } \\
\text { ence their choices, is it fair to share personal data with these } \\
\text { others? }\end{array}$ \\
\hline 4 & $\begin{array}{l}\text { Brain health } \\
\text { and challeng- } \\
\text { ing the us- }\end{array}$ & $\begin{array}{l}\text { Should the technology challenge the user (stretching person to } \\
\text { contribute to brain health), or should it just give the person ac- } \\
\text { cess to the information they want (keeps them happy but not }\end{array}$ \\
\hline
\end{tabular}




\begin{tabular}{|c|c|c|}
\hline & er/senior & necessarily optimizing/extending brain health)? \\
\hline 5 & $\begin{array}{l}\text { Managing } \\
\text { risk/safety }\end{array}$ & $\begin{array}{l}\text { Loss of physical liberty versus freedom of movement } \\
\text { a. Use of automatic door locking } \\
\text { b. Use of sensors tracking location and movement } \\
\text { Should technology raise an alarm for staff members and others, } \\
\text { if specific care tasks not undertaken? }\end{array}$ \\
\hline 6 & Data protection & $\begin{array}{l}\text { Data analytics and clinical decisions } \\
\text { Resident access to own data } \\
\text { Permissions for others to access (sharing of data with family } \\
\text { members) }\end{array}$ \\
\hline 7 & $\begin{array}{l}\text { Lifestyle } \\
\text { choices and re- } \\
\text { sponsibilities }\end{array}$ & $\begin{array}{l}\text { Use of technology to manage distribution of food (prevent resi- } \\
\text { dent eating food that might make them sick) } \\
\text { Use of technology to track eating habits and behavior of resident } \\
\text { (frequency, swallow risk) }\end{array}$ \\
\hline 8 & $\begin{array}{l}\text { Resident sur- } \\
\text { veys }\end{array}$ & $\begin{array}{l}\text { Should a resident be required to complete surveys capturing da- } \\
\text { ta about what food eating, pain levels and management of pain, } \\
\text { stress and mood? }\end{array}$ \\
\hline 9 & $\begin{array}{l}\text { Unethi- } \\
\text { cal/illegal be- } \\
\text { havior }\end{array}$ & $\begin{array}{l}\text { Use of technology to detect and manage unethical or illegal be- } \\
\text { havior of residents or carer's or family }\end{array}$ \\
\hline
\end{tabular}

\subsection{Appendix 5: Senior User Interface}

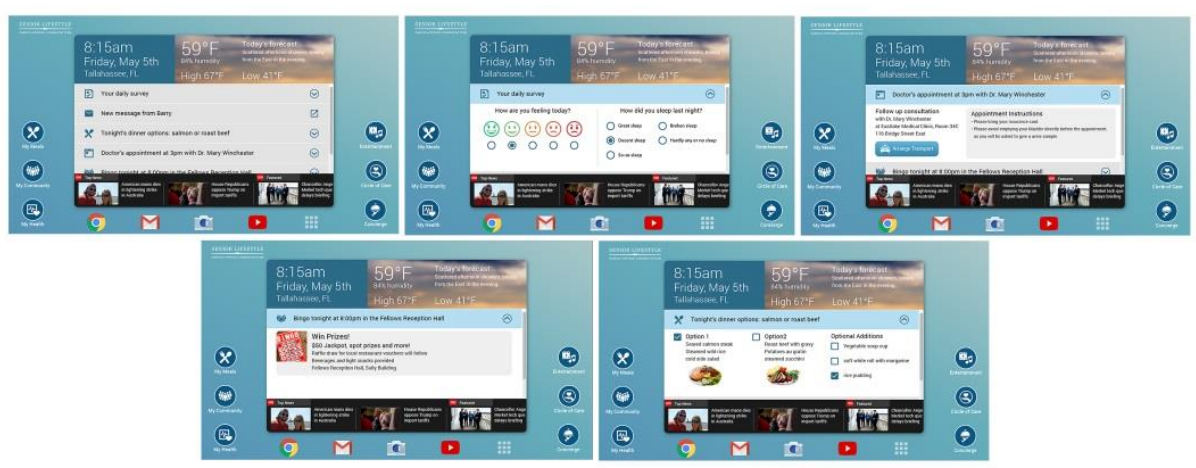

Figure 2: Resident Screens - Example Prototype

\subsection{Appendix 6: Nurse User Interface}
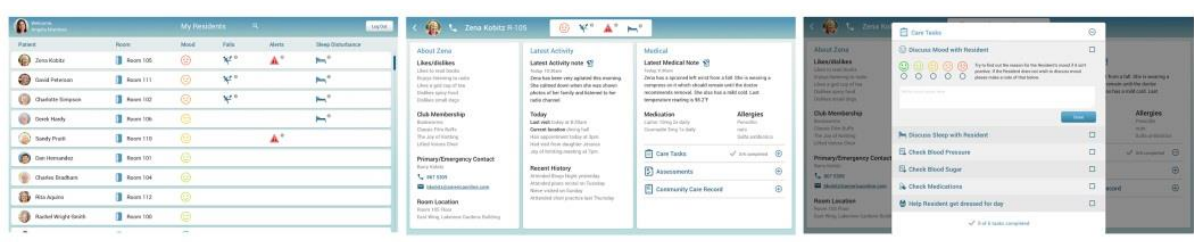

Figure 3: Nurse Rounding Screens - Example Prototypes 